\title{
Incentivando o Ingresso de Mulheres nos Cursos de Engenharia e Tecnologia
}

\author{
Marcelly Homem Coelho ${ }^{1}$, Morgana Sartor ${ }^{1}$, Luciana Bolan Frigo ${ }^{1}$, Eliane \\ Pozzebon ${ }^{1}$ \\ meninasdigitaisufsc@gmail.com, luciana.frigo@ufsc.br
}

\begin{abstract}
This article describes a workshop with Computer Engineering undergraduate young women and high school girls where the former give classes to the latter. The purpose of the workshop is to provide real experience with usually abstract concepts of electronics and technological subjects. The high school girls' challenge was to make a prototype automation doll house (domotics) using their knowledge. The project's main goal is for high school girls to experience and explore a field traditionally dominated by men, with the intention of enabling them to reflect and expand their career possibilities to include opportunities within the technological area as well as help in building new skills.
\end{abstract}

Resumo. O presente artigo descreve uma experiência de interação entre estudantes de graduação do curso de Engenharia de Computação com um grupo de alunas do Ensino Médio, por meio da realização de uma oficina. $O$ objetivo da oficina é de proporcionar uma experimentação real acerca dos conceitos abstratos de eletricidade, eletrônica e tecnologia. O desafio das alunas foi de conhecer a domótica, realizando um protótipo de automação de uma casa de bonecas. O principal objetivo do projeto é que as meninas possam experimentar e explorar um campo tradicionalmente dominado $e$ vivido pelos homens, a fim de que elas possam refletir e expandir suas possibilidades de carreira incluindo a área de exatas no rol de oportunidades, além de auxiliar na construção de novas habilidades e competências.

\section{Introdução}

A desproporcionalidade da representação das mulheres em áreas tecnológicas como na eletrônica, por exemplo, possui causas variadas, sejam estas de ordem sociocultural, econômica ou cognitiva. O desenvolvimento de tecnologia ainda é considerada por grande parte da população como sendo intrínseca ao universo masculino. E desta forma, é fortemente difundido na sociedade que a mulher não possui talentos para as ciências exatas, mesmo que historicamente elas tenham conquistado papéis importantes na área da tecnologia, como por exemplo, o fato do primeiro algoritmo ter sido escrito por Ada Lovelace, mostrando que as mulheres possuem competências para atuarem nesta profissão, conforme Coelho et al. (2015).

Existem vários estudos que tem como objetivo entender os motivos que levam à diminuição do número de garotas em áreas de tecnologia e computação. De acordo com Teague (2002), uma das razões para essa redução é o fato das garotas terem uma percepção equivocada sobre as carreiras da computação fazendo com que a grande maioria delas opte por cursos mais tradicionais. 
Para incentivar o aprendizado dos estudantes é de suma importância buscar alternativas para proporcionar um processo de ensino-aprendizagem atraente e um ambiente motivador. Um dos motivos de utilizar tecnologias é esclarecido no livro Connected Code - Why Childen Need to Learn Programming de Kafai e Burke (2014), o qual afirma que os computadores se tornaram acessíveis dentro e fora do ambiente escolar, despertando assim um interesse em aprender estas tecnologias.

Moratori (2003) ressalta que utilizar recursos tecnológicos torna possível potencializar o desenvolvimento de competências diversas, uma vez que possibilita a reestruturação do modo como alunos e professores se relacionam.

Introduzir tecnologias como forma de entretenimento e fazer com que se torne também um momento de troca de conhecimento e aperfeiçoamento dos assuntos abordados em sala de aula é uma ótima maneira de instigar alunas do Ensino Médio a correlacionarem e solidificarem seus aprendizados (Coelho et al. 2015).

Neste contexto, surge a proposta do projeto de extensão Meninas Digitais - UFSC que realiza oficinas de diferentes temas que utilizam práticas pedagógicas modernas buscando apresentar profissões voltadas à computação e engenharias e de promover a reflexão sobre os papéis desempenhados por homens e mulheres nestas áreas.

\section{Condução das oficinas}

Com o intuito de mitigar o impacto negativo do senso comum que relaciona tecnologia a profissões masculinas que o Projeto Meninas Digitais - UFSC oferece oficinas e palestras de diversas áreas tecnológicas para incentivar meninas do Ensino Médio a obterem interesse na área da computação. As oficinas são ministradas por alunas do curso de Engenharia de Computação que fazem parte do projeto.

Neste artigo será descrita a oficina de iniciação à eletrônica, realizada em 2015, que faz uso do kit didático de eletrônica LittleBits (Fitzpatrick e Aneja, 2015), (LittleBits, 2016) onde as peças e componentes do circuito não estão conectadas a um protoboard e se encaixam umas as outras por contato e permanecem conectadas por atração magnética.

A oficina segue a seguinte ordem: (i) aplicação de um questionário inicial; (ii) distribuir apostilas com informações importantes sobre cada grupo de peças, sua utilização e aplicações; (iii) apresentar conceitos básicos de circuitos; (iv) mostrar as principais funcionalidades do kit; (v) propor uma situação problema que no caso foi de realizar a automação de uma casa de boneca, conforme ilustra a figura 1 e (vi) aplicação do questionário final. 


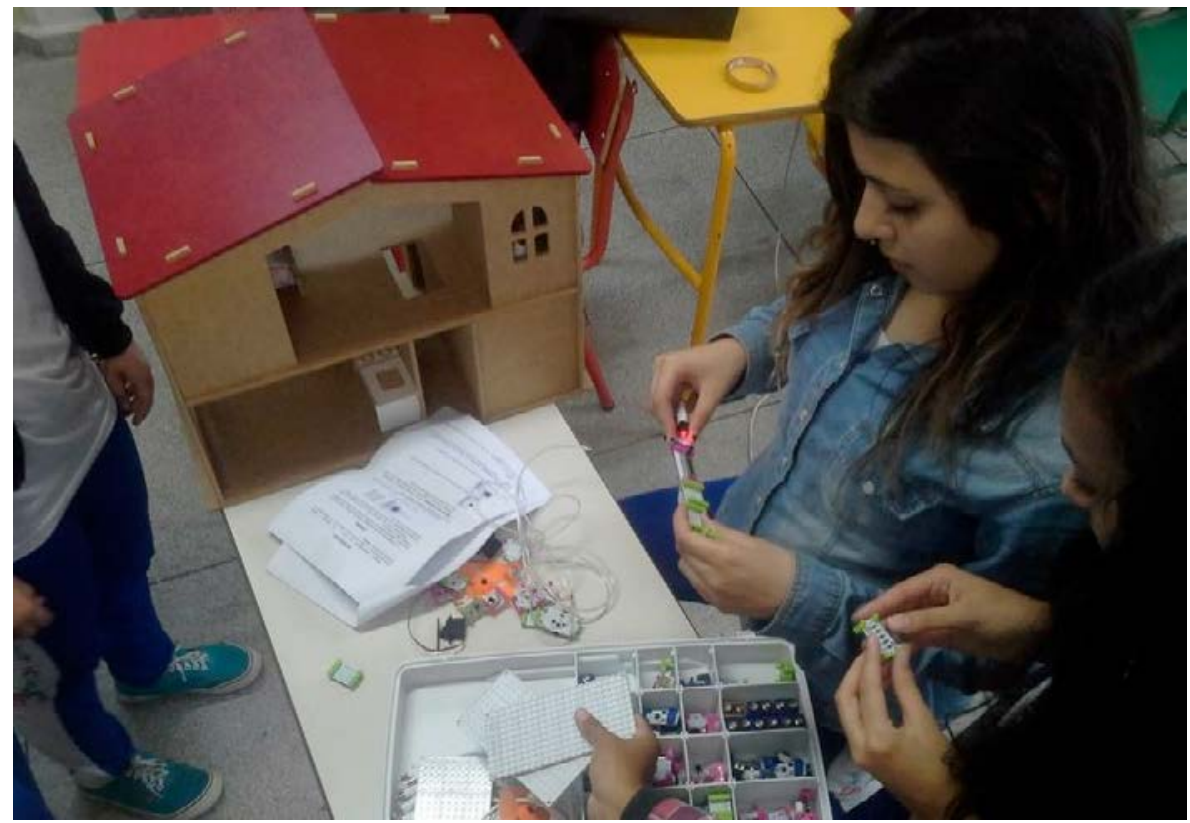

Figura 1: Desenvolvimento da automação residencial.

A oficina aconteceu no laboratório de informática com um grupo de oito alunas, selecionadas previamente pela escola, o pequeno número de alunas, se justifica pelo fato da oficina ter ocorrido na final do ano letivo e muitas alunas que estavam estudando para o vestibular, não quiserem participar desta oficina.

Foi feita uma atividade demonstrando o uso do kit e na sequência as alunas deveriam solucionar, com os materiais disponíveis, o problema apresentado. $\mathrm{O}$ desafio envolveu conceitos de circuitos eletrônicos com aplicações em automação residencial, estimulando e fortalecendo o raciocínio lógico, além de provocar um estímulo de reflexão sobre as possibilidades de perfil do profissional atuante nesta área. A Figura 2 mostra o resultado da atividade de automação residencial realizada pelas alunas: (i) automação do portão; (ii) uso de sensores para acendimento automático das lâmpadas, (iii) efeitos sonoros etc. Os circuitos são desenvolvidos em grupos e qualquer uma das garotas poderia se registrar no site do LittleBits e publicar o projeto elaborado em sala, compartilhando o conhecimento adquirido com a comunidade que faz uso do kit ao redor de todo o mundo. 


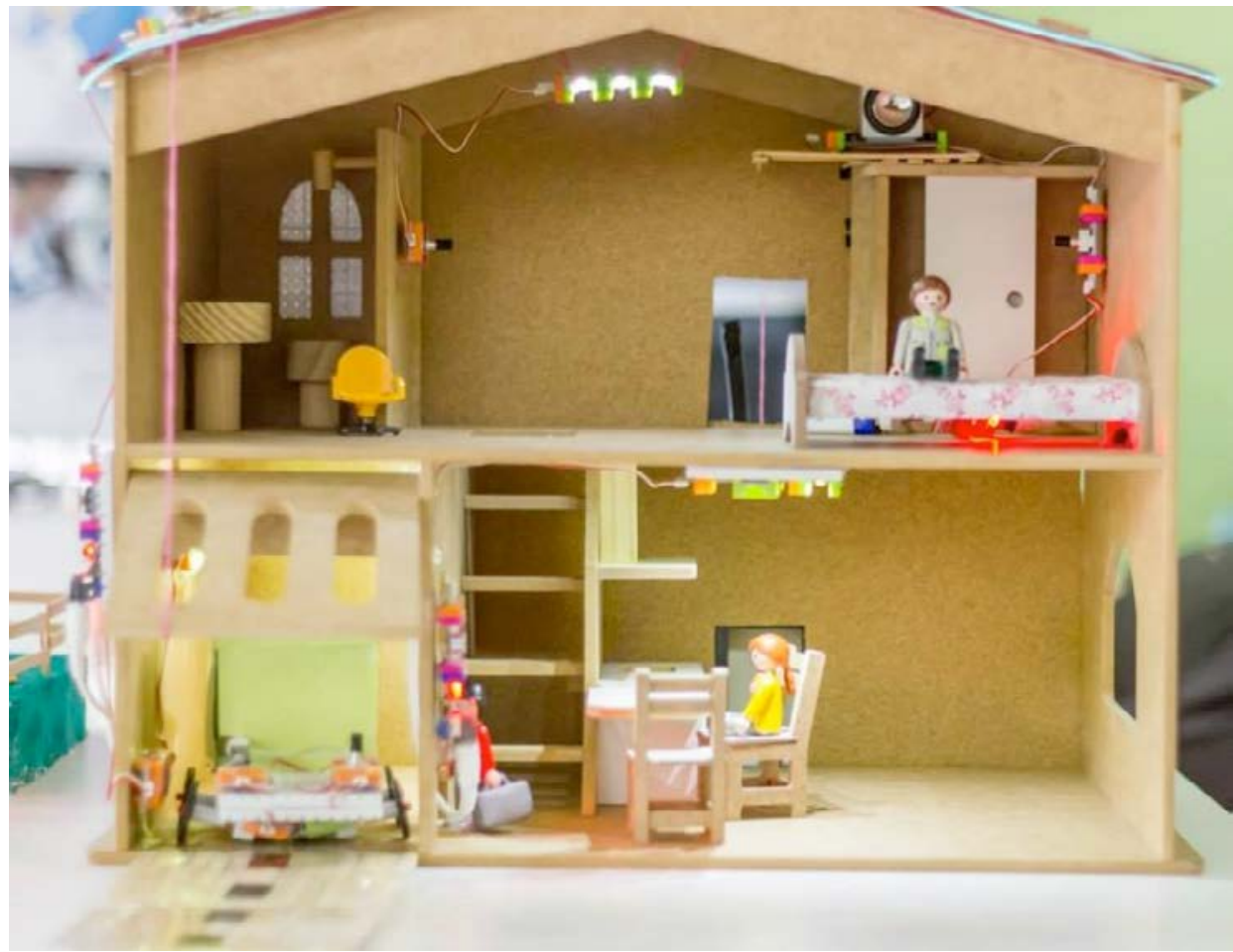

Figura 2: Casa de boneca automatizada pelas estudantes.

\section{Resultados da Oficina e Conclusão}

$\mathrm{Na}$ oficina aqui relatada, participaram oito alunas do ensino médio, que responderam aos questionários inicial e final. A primeira pergunta tinha o objetivo de constatar se elas já haviam tido algum contato com a montagem de um circuito elétrico. A grande maioria das alunas $(87,5 \%)$ não tinha qualquer contato anterior com a construção de circuitos elétricos.

Quando questionadas sobre uso do kit LittleBits, por unanimidade, as participantes avaliaram que esse recurso tecnológico proporcionou à oficina a característica de ser mais interessante e dinâmica, uma vez que o minicurso possibilitou experiências não encontradas no ensino médio tradicional.

Em comparação aos resultados do questionário inicial, observou-se que as novas respostas, relacionadas ao interesse das estudantes em aprender mais sobre circuitos, foram gratificantes e motivadoras, pois todas demonstraram interesse.

No que diz respeito às alunas de Engenharia de Computação, a realização de oficinas é uma maneira de reforçar conhecimentos e realizar experiências práticas, pois algumas experimentações não são oportunizadas ao longo do curso.

Este artigo tem como finalidade relatar suscintamente a experiência de uma oficina prática de circuitos eletrônicos, que teve sucesso na sua realização em proporcionar um modelo alternativo e que pode ser replicado em outras instituições de ensino. 


\section{Agradecimentos}

Agradecemos o apoio do CNPq/VALE S.A. N N $^{\circ}$ 05/2012 - Forma-Engenharia,

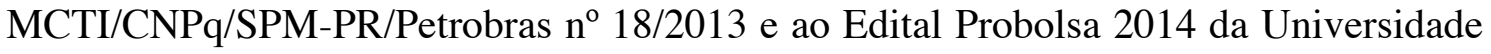
Federal de Santa Catarina.

Agradecemos também a Escola Jovem Dite Freitas - Tubarão/SC e ao Instituto Alcoa.

\section{Referências}

COELHO, M. H. ; FRIGO, L. B. ; CARDOSO, J. P. ; SOUZA, R. F. ; POZZEBON, E. (2015) O Desafio de Mudar o Papel das Mulheres na Indústria de Games. In: Computer on the Beach, 2015, Florianópolis. Anais do Computer on the Beach. p. 249-258.

FITZPATRICK, A.; ANEJA, A. (2015) LittleBits Are Like Electronic Legos For Kids and Adults. TIME. Disponível em: < http://time.com/4022048/littlebits/>.

KAFAI, Y. B.; BURKE, Q. (2014) "Connected Code: Why Children need to learn programming", Cambridge: The Mit Press.

LITTLEBITS (2016) Disponível em: < http://littlebits.cc>

MORATONI, P. B. (2003) "Por Que Utilizar Jogos Educativos no Processo de Ensino Aprendizagem?" Trabalho de Conclusão de Curso. UFRJ. Rio de Janeiro. Disponível em:

<http://www.nce.ufrj.br/ginape/publicacoes/trabalhos/t_2003/t_2003_patrick_barbosa_ moratori.pdf>

SANTO, P., E. (2008) "Os estudos de gênero na ciência da informação". Em Questão, Porto Alegre, v. 14, n. 2, p. 317 - 332, jul./dez.

TEAGUE, J, (2002) “Women in computing”. SIGCSE Bulletin, v. 34, n. 2, p. 147. 